\title{
Las narrativas de la toponimia en el Sitio de Memoria "Venda Sexy - Discoteque": discursos y contextos en el Chile actual
}

\author{
The narratives of toponymy in the Site of Memory "Venda Sexy - \\ Discoteque": discourses and contexts in present-day Chile
}

\author{
Vania Reyes Muñoz* \\ Yafza Reyes Muñoz**
}

\begin{abstract}
Resumen
El texto argumenta que la toponimia que registra el Sitio de Memoria "La DiscotequeVenda Sexy" alude a una representación literal sobre la naturalización de la tortura durante la dictadura cívico-militar chilena, en particular, la violencia sexual contra mujeres. Dicho relato es una construcción contextual a partir del proceso de articulación feminista de los últimos años en Chile, y se hace más patente tras la violencia policial desatada contra quienes fueron parte de las manifestaciones acaecidas durante el estallido social de octubre de 2019, donde nuevamente mujeres y niñas fueron sujetas de torturas, tratos degradantes y violencia sexual. El texto analiza la toponimia de las palabras discoteque, venda y sexy; además, evidencia la relevancia del Estado en el mantenimiento de la memoria y pone en discusión el papel de la ciudadanía y los colectivos de sobrevivientes del horror político en la conservación y posesión, material y simbólica, de los sitios de memoria.
\end{abstract}

Palabras claves: violencia política, torturas, Sitio de Memoria "La Discoteque - Venda Sexy"

\footnotetext{
* Vania Reyes Muñoz es doctora (c) en Estudios Urbanos de la Pontificia Universidad Católica de Chile, patrocinada por CONICYT/ANID 2019-2023 y COES (Centre for Social Conflict and Cohesion Studies, ANID/FONDAP 15130009). Investiga en las áreas de geografía cultural y género. Vania es parte de la Asociación de Geógrafas Feministas de Chile

${ }^{* *}$ Yafza Reyes Muñoz. Antropóloga especializada en estudios de Género (Universidad de Chile) y en estudios Afrolatinoamericanos (ALARI Harvard University). Doctora en Ciencias Sociales por la Universidad Católica San Antonio de Murcia, España. Temas de investigación: interseccionalidad género, clase y raza en la inmigración afrodescendiente en Chile; feminismos decoloniales y metodologías críticas para la investigación con población inmigrante; salud intercultural y derechos humanos. Colabora con organizaciones de derechos de mujeres, infancias transgéneras y ciudadanías migrantes.
} 


\begin{abstract}
Text argues that the toponymy recorded at the Site of Memory "La Discoteque-Venda Sexy" alludes to a literal representation of the naturalization of torture during the Chilean civil-military dictatorship, particularly sexual violence against women. This narrative is a contextual construction from the process of feminist articulation of recent years in Chile and becomes more evident after the police violence unleashed against those who were part of the demonstrations that occurred during the social movement of October 2019, where again women and girls were subjected to torture, degrading treatment and sexual violence. The text, which analyses the toponymy of the word: discotheque, bandage and sexy. Also, evidences the relevance of the State in the maintenance of memory and discusses the role of citizenship and the collectives of survivors of political horror in the conservation and possession, material and symbolic, of the sites of memory.
\end{abstract}

Keywords: political violence, torture, Site of Memory "La Discoteque - Venda Sexy"

Fecha de recepción: Mayo 2021

Fecha de aprobación: Diciembre 2021

\title{
Introducción
}

Al comenzar el texto nos guiamos de las palabras de Arendt al señalar que es el Estado, en tanto la burocracia estatal, los medios de comunicación y los perpetradores, entre otros, quien hace parte de una maquinaria que busca que lo criminal se presente como legal e incluso legítimo, para amparar la ejecución de violencia política hacia los grupos que éstos han determinado construir como enemigos internos. Este aparataje institucional busca la complicidad de una sociedad para perpetrar sus atrocidades (Arendt, 1999).

En ese contexto, la violencia política al inicio del periodo de dictadura militar en Chile, entre los años 1974 y 1977, fue quizás la más cruenta y sistemática de los 17 años que estuvo en el poder Augusto Pinochet y la Junta Militar (1973-1990). En este trabajo se argumenta que el sitio de memoria y ex centro de tortura y exterminio" "La Discoteque -

1 En 1974 el equipo de Carabineros de la Agrupación Águila de la Dirección de Inteligencia Nacional (DINA), que funcionaba en el centro de torturas, realizó una gran cantidad de detenciones, mayoritariamente jóvenes universitarios y militantes del Movimiento de Izquierda Revolucionario (MIR). Según cifras del Programa de Derechos Humanos del Ministerio del Interior, en este centro de tortura hubo 27 detenidos desaparecidos, 77 detenidos sobrevivientes y 26 procesos judiciales asociados (https://www.patrimoniocultural.gob.cl). Se estima que, en el breve periodo de funcionamiento intensivo del centro, más de un tercio de las y los prisioneros que por 
Venda Sexy", constituye en su toponimia una representación espacial literal sobre la naturalización de las prácticas de tortura del periodo y, en particular, sobre los cuerpos de mujeres. Esto porque su denominación, así como cada uno de los elementos que describe, permiten hacer una lectura sobre la asignación de significado, y los contextos en los cuales estos significados son disputados, pasando del uso común dado por los agentes de la Dirección de Inteligencia Nacional (DINA) que ahí operaron, a aquellos significados otorgados en la actualidad por quienes estuvieron prisioneras y prisioneros. Además, como señala Dwyer y Alderman (2008), permite situar hoy en día estos elementos como parte esencial de las narrativas del Sitio y que le posicionaron para ser declarado Monumento Nacional. Al mismo tiempo, se busca disputar la construcción de una memoria feminista, como lo refleja la información que se ha podido recopilar en medios de comunicación online, nacionales y extranjeros, así como en las diferentes actividades desarrolladas por colectivos de mujeres sobrevivientes a la prisión política y tortura de éste y otros centros, principalmente, "Mujeres Sobrevivientes Siempre Resistentes" y "Memorias de Rebeldías Feministas". El texto tiene por objetivo discutir la relevancia de la toponimia del Sitio en la disputa de una memoria feminista, entendiendo las toponimias como una forma espacial, material y simbólica, que, anclada al territorio, permite procesos de memorialización sobre la violencia política sexual ejercida sobre las mujeres.

A fin de desarrollar esta argumentación, el texto inicia con una descripción del Sitio de Memoria "La Discoteque - Venda Sexy". Luego, argumenta el rescate de estos elementos espaciales, tanto en la denominación del Sitio de Memoria a través de la categoría de Monumento Nacional, como en la construcción de una memoria feminista. Para ello nos basamos en la idea de que la protección de este espacio se hace parte en una estrategia que apunta a visibilizar la violencia política y sexual contra las mujeres y cuyo fin es el reconocimiento, tipificación y sanción legal de ésta como una práctica sistemática y persistente en las estructuras del Estado, en particular, policial y judicial. Práctica que fue ejercida en la época de dictadura y que persiste en el accionar de las policías, como lo revelan las numerosas denuncias de violencia policial sexual a partir del movimiento social del 18 de octubre del año 2019 en Chile.

En términos teórico-metodológicos se acude a las "toponimias" que, desde la perspectiva cultural de la geografía, proponemos construir como categoría para leer las relaciones entre espacialidad y memoria. En un marco en el cual estas relaciones, a la

ahí pasaron fueron asesinados o hechos desaparecer, siendo el lugar con mayor proporción de víctimas con causa de muerte de los centros de tortura de la época (donde la proporción de muertos es menor al $10 \%$ del total de prisioneros). Igualmente, del total de prisioneros llevados a la "Discoteque - Venda Sexy" cerca del $40 \%$ fueron mujeres, lo que revela una proporción desmedida en relación con los otros recintos de la DINA, donde lo común era aproximadamente un $20 \%$ de mujeres dentro del total de prisioneros (Matta, P. (16 de agosto de 2019) La Venda Sexy y la invisibilización de la mujer [Blog Institucional]. Colegio de Arqueólogos y Arqueólogas. https://colegiodearqueologos.cl/la-venda-sexy-y-la-invisibilizacion-de-la-mujer/ 
vez que dan cuenta de expresiones materiales y simbólicas que conllevan los procesos de memorialización (Raposo, 2017), también reflejan un anclaje de sitio, un territorio en disputa de sus significados.

El texto se estructura en tres apartados, el primero hace una descripción del hoy Sitio de Memoria, ex centro de tortura y exterminio, y de las atrocidades que ahí se cometieron. El segundo se refiere a la construcción de las toponimias como categorías descriptivas que dan cuenta de representaciones socioespaciales sobrepuestas en esta casa habitación. El tercero hace alusión a las reflexiones contextuales y finales para la comprensión de la relevancia que tiene el reciente y primer fallo con enfoque de género en los crímenes de lesa humanidad cometidos por los agentes del Estado en el periodo de dictadura cívico-militar. Esto como parte de la construcción de una memoria feminista y como una forma de denuncia de la mantención de prácticas de violencia de género por parte de las policías y otros agentes del Estado. Las conclusiones apuntan al rol del Estado y las políticas de memoria, a la vez que abren la discusión al papel de la ciudadanía y los colectivos de sobrevivientes del horror político en la conservación y posesión de los sitios de memoria.

\section{La Discoteque - Venda Sexy}

El ex centro de tortura y exterminio está ubicado en la calle Irán \#3037, en la intersección con calle Los Plátanos en la comuna de Macul, región Metropolitana de Santiago. Funcionó desde finales de 1974 (noviembre y diciembre) y hasta inicios de 1975 (enero, febrero y marzo) de manera continua y luego de manera esporádica hasta 1981. Sus nombres se deben a que las y los prisioneros llegaban y permanecían con la vista vendada, mientras eran sometidos a torturas de toda índole y en particular sexual, vejaciones y violaciones (Informe Valech, 2005), a la vez que sonaban bandas británicas y latinas a alto volumen para disimular los gritos de las y los detenidos.

En este centro de tortura, dirigido por Raúl Iturriaga Neumman², a diferencia de otros centros y, quizás debido a que se localizaba en un entramado residencial, con casas vecinas en dos de sus cuatro costados -los otros dos costados dan a las calles Irán y Los Plátanos, respectivamente-, las torturas se realizaban en horario de oficina. Las y los sobrevivientes señalan que el sótano era el lugar principal de torturas de los agentes y que fuera del horario de torturas "oficial" se cometían crímenes de violación de las

2 En el año 2007 la Corte Suprema comenzó a rebajar las condenas por crímenes de lesa humanidad, en base al criterio de "irreprochable conducta anterior". Los familiares de detenidos desaparecidos en las causas por las que fue procesado Iturriaga, así como las y los sobrevivientes a las torturas que muchas veces el mismo ejecutó, señalaron que el actuar de los jueces de la Sala Penal de la Corte Suprema fue arbitrario, restableciendo la impunidad e injusticia que han debido hacer frente desde el retorno de la Democracia. (Memoria Viva; 2019). 
detenidas por parte de los guardias del recinto en las habitaciones del segundo piso. Todos estos actos por años fueron catalogados como torturas en términos genéricos en los informes de verdad y justicia, e incluso se reemplazó la palabra "violación" en los testimonios de las mujeres por "tratos degradantes", por ejemplo, en los Informes de la Vicaría de la Solidaridad, de acuerdo a los testimonios señalados por las sobrevivientes (Arellano, 2020). Esto da cuenta de que la violencia política del Estado, y su posterior denuncia, fue diferenciada y desigual sobre los cuerpos de las mujeres detenidas ${ }^{3}$, al omitir hechos fundamentales sobre el horror de los actos cometidos a sus cuerpos.

Según la información obtenida del archivo digital de las violaciones a los Derechos Humanos por la Dictadura Militar en Chile (1973-1999) en el sitio web Memoria Viva (2019), la Venda Sexy no habría sido reconocida por parte de la Junta Militar y su tenencia no habría podido ser constatada en las actas entregadas por la DINA hasta el año 1980, de acuerdo con lo declarado por el ministro del Interior de Pinochet, Sergio Fernández en 1979. Al año siguiente (1980), el exagente Manuel Contreras reconoció el cuartel como propiedad de la DINA (Dirección de Inteligencia Nacional) y luego de la CNI (Central Nacional de Inteligencia), sin entregar mayores antecedentes respecto de las operaciones que en él se realizaron.

El 3 de octubre del año 2016 se firmó el decreto número 277 que declaró el inmueble y ex centro de tortura y extermino como Monumento Nacional en la categoría Monumento Histórico refiriéndose al Sitio de Memoria "Venda Sexy - Discoteque"4, como uno de:

Los primeros centros de detención de la DINA durante el periodo denominado por el Informe Valech como de Detención Selectiva, entre los años 1974 y 1977. El recinto estuvo a cargo del Mayor del Ejército Gerardo Ulrich, dependiente de la Brigada Purén, dirigida por el Mayor General del Ejército Raúl Iturriaga Neumann. En el recinto operaron las agrupaciones Chacal, dirigida por el oficial de Carabineros de Chile, Miguel Hernández Oyarzo, y la Agrupación Ciervo, a cargo del Oficial del Ejército Manuel Carevic Cubillos, además de la Mayor de Carabineros Ingrid Olderock. [Cursiva propia] (Consejo de Monumentos Nacionales [CMN] D²77/2016, pf.2)

\footnotetext{
${ }^{3}$ Beatriz Bataszew, sobreviviente del ex centro de tortura, activista feminista e integrante del Colectivo de Mujeres Sobrevivientes Siempre Resistentes y ex integrante de la Coordinadora Feminista 8M, junto a otras compañeras de tortura y presidio en éste y otros centros de detención de la DINA, han dedicado gran parte de su activismo a visibilizar la violencia política sexual sobre las mujeres detenidas.

${ }^{4}$ Solicitud que fue ingresada por Roberto D'Orival Briceño, Tania Toro Spuler y Sady Arenas, representantes de la Asociación de Memoria y Derechos Humanos de Macul "Venda Sexy",.
} 
Se lee en el Decreto de Declaración Patrimonial ${ }^{5}$ que el centro de detención se caracterizó por llevar "al límite la capacidad de castigar e infligir daño, efectuando diversos tipos de torturas sexuales, algunas con animales, a cargo de la Mayor de Carabineros Ingrid Olderóck" (CMN D²77/2016, pf.3), lo que incluía el asesinato y desaparición de las y los prisioneros. Además, se hace referencia al procedimiento de tortura y la distribución de los espacios dentro de la casa, haciendo una recreación de los hechos y elementos, en los que se relata,

Las prisioneras y los prisioneros eran ingresados en automóviles que aparcaban en el patio y eran escuchados al ingresar por el sonido de las ruedas en la gravilla. En el primer piso del inmueble, el living era utilizado como sala de recepción y de identificación de los detenidos. Luego, eran separados según sexos en dos habitaciones, a los costados de la escalera que da al segundo piso. Al lado de la escalera estaba el baño utilizado por las detenidas y los detenidos. En las piezas del segundo piso se realizaban las violaciones y torturas; Que, el subterráneo al que se accede por el patio posterior a través de la cocina, o desde el patio delantero, fue el lugar donde se propinaban torturas y violaciones con un perro pastor alemán adiestrado por Ingrid Olderóck; (CMN D²77/2016, pf.5 y 6)

$Y$, entre los fundamentos patrimoniales de su Declaratoria se indica que: "Es un testimonio de la discriminación de género aplicado en las torturas sexuales por parte de los agentes de Estado durante la dictadura, cometiendo violaciones sistemáticas a los Derechos Humanos, la dignidad, el cuerpo y la sexualidad las prisioneras" (CMN D²77/2016, pf.10). Dicho, esto, la Declaración señala que los atributos relevantes del monumento son:

1. La ventana circular del baño del primer piso.

2. La escalera de mármol que conecta el primer y el segundo piso.

3. Las habitaciones del segundo piso.

4. La placa memorial.

\footnotetext{
${ }^{5}$ El Decreto hace oficial la aprobación de la solicitud de Declaración de Sitio de Memoria sucedida en la sesión del CMN, de manera mayoritaria, aunque no unánime, el 11 de mayo del año 2016. En el Decreto se indican como fundamentos patrimoniales: la representatividad del centro dentro del periodo de Detención Selectiva; la brutalidad de los métodos de tortura, desaparición y vulneración de la dignidad de la persona humana; la discriminación de género en su operar, la focalización en la detención de jóvenes universitarios de partidos opositores y su contribución, de preservarse, a la promoción de los DDHH.
} 


\section{La escalera y subterráneo del patio trasero6;}

Todos estos son elementos materiales descritos por las y los sobrevivientes en sus relatos. Además del área relativa al monumento -la casa y el predio-, que también estaría protegida, con una superficie aproximada total de 1003,19 mts2 y una superficie construida de 290 mts.2 y el contorno de la Placa Memorial, ubicada enfrentando el inmueble en la Plaza Arabia, también son parte de este patrimonio. No obstante, y pese a la declaratoria, el inmueble continúa en manos de privados y a finales del año 2019 la prensa indicó la venta del sitio $^{7}$ a una Sociedad de Inversiones Inmobiliarias, lo que puso en duda la mantención de la materialidad del inmueble ${ }^{8}$. A continuación, el Plano Oficial de la Declaratoria de Monumento Nacional.

\footnotetext{
6 Sótano que aún se mantiene sin intervención tras el arrendamiento y compra de sucesivos dueños. El propietario del inmueble hasta el 2019, indicó que en este subterráneo había documentación alusiva a nombres; sin embargo, él no la resguardó porque desconocía el uso que había tenido la casa durante la dictadura. Además, indicó que siempre estuvo dispuesto a que se realizaran peritajes en la casa, pero que las autoridades no se acercaron a solicitar algún tipo de información. Se suma la presencia de un pozo (cámara subterránea sin escotilla), que no ha sido peritado. (Memoria Viva. (2019).

7 Ante lo cual, numerosas organizaciones vinculadas a DDHH realizaron una declaración en rechazo a la venta del inmueble y criticaron el rol pasivo del Estado y la mantención de la impunidad frente a los escenarios de violación a los DDHH sucedidas en democracia.

${ }^{8}$ Según la información consultada, la casa donde funcionó el centro de tortura y exterminio era de propiedad de una familia comunista, obligada al exilio tras el golpe de Estado. El inmueble fue arrendado mediante un tercero por el teniente de Carabineros y miembro de la Dirección de Inteligencia Miguel Eugenio Hernández Oyarzo. En 1981, el propietario al enterarse del uso al que se había destinado la casa decidió venderla. Tras ser adquirida por vecinos que intentaron instalar hospedería y guardería sin éxito, la casa fue nuevamente puesta en venta y comprada por un empresario industrial quien, tras vivir varios años ahí, habría vendido el inmueble el año 2019. Siendo actualmente el Sitio de propiedad de la sociedad Inversiones Arriagui Limitada. No obstante, según la información proporcionada por Bataszew en septiembre del 2021, el empresario continuaría habitando la casa
} 


\section{Figura 1: Plano Oficial Declaratoria Monumento Nacional (CMN D`277/2016).}

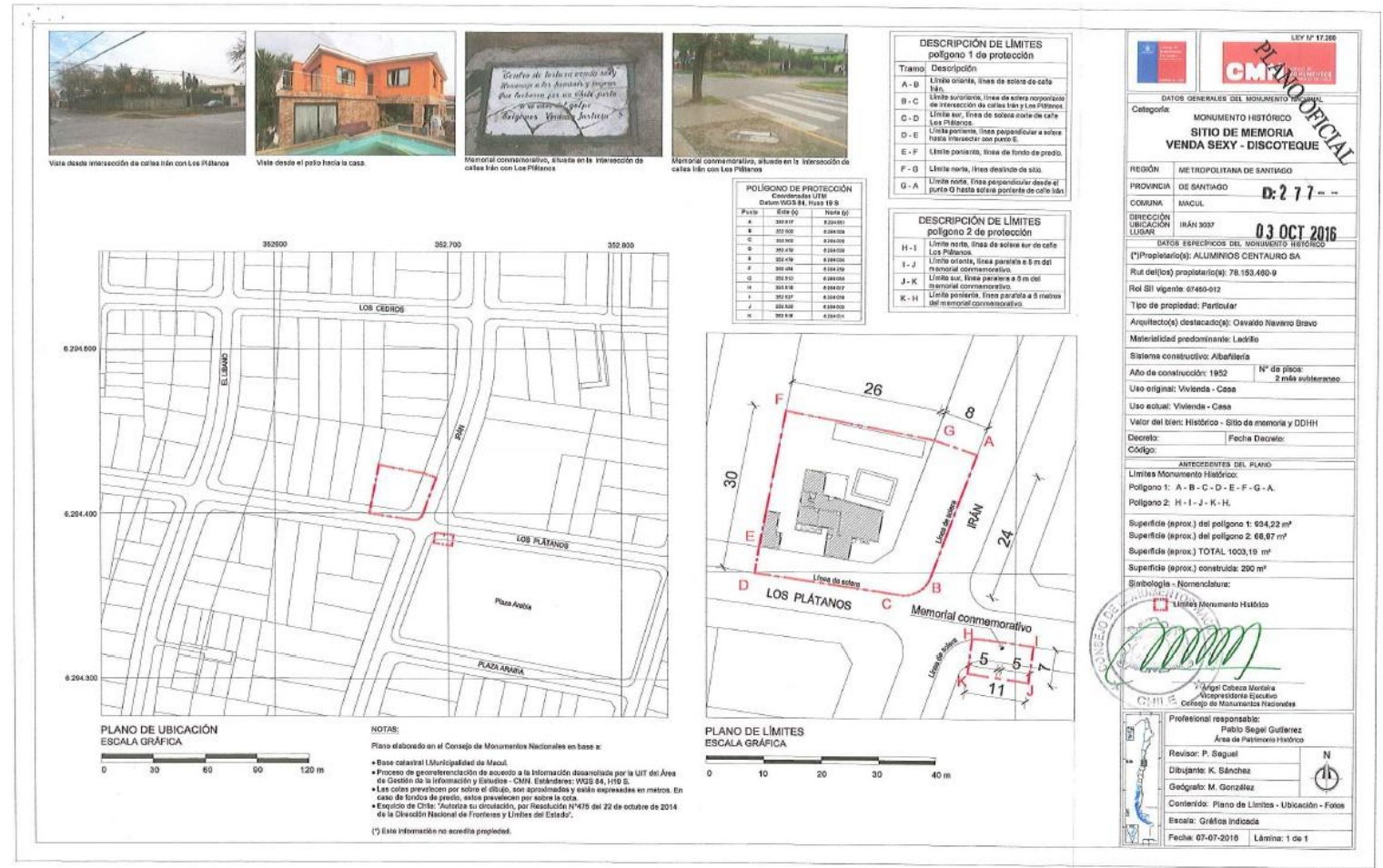

Fuente: CMN (2016).

\section{Las representaciones en la toponimia del lugar como traducción de la tortura desde el espacio privado e invisibilizado, al espacio público y nombrado.}

En el apartado se construye sintéticamente la categoría de "toponimia" para describir las relaciones materiales y simbólicas que se anclan a un territorio y cuyo significado se disputa a través de la "representación" que éstas conllevan (2.1). Luego se revisa cada una de las representaciones circunscritas en la toponimia del lugar (2.2), primero en relación con la Discoteque, que apela a la construcción sonora que marca los tiempos y frecuencias de la práctica de torturas. Venda, en la anulación de la vista como forma de control, desorientación espacial e imposibilidad de reconocimiento y, finalmente, Sexy en las representaciones de los cuerpos femeninos, jóvenes y resistentes, que había que someter, como señala Segato (2014) en una forma de mantener el orden y jerarquía socioespacial. Lo que en las palabras de unas de las sobrevivientes tuvo "un sentido claramente político contrainsurgente para impedir o castigar a las mujeres que luchan por sus derechos o contra las opresiones" (Arellano, 2020) 
Revista Punto Género N.16 Diciembre de 2021

ISSN 2735-7473 / 24- 50

\subsection{Toponimias de la memoria}

La toponimia busca el origen de la palabra y se define como un quehacer interdisciplinario (Cerrón-Palomino, 2015); para este texto, la toponimia es una forma espacial que hace alusión ineludible a un sitio, el sitio de memoria en este caso, como un marca material y simbólica distinguible en el territorio (Raposo, 2017). La configuración del nombre, del acto de nombrar un sitio implica un acto de poder y un reconocimiento de lo que significa este sitio para un grupo, que sobrepasa su función elemental de ubicar y orientar a otros en el espacio. De ahí que la toponimia de sitio conlleva la posibilidad de ritualidad y de perpetuar el significado anclado como testimonio de origen en el topónimo.

Los topónimos son eminentemente descriptivos, dan cuenta de un contexto que va desde lo geográfico a lo histórico, cultural y conmemorativo (Cerrón-Palomino, 2015). En este caso "un espacio conmemorativo correspondería a un espacio que logra movilizar "un recordar juntos", incorporando las selecciones de aquello memorable, así como las afinidades e identidades compartidas por el grupo involucrado en la articulación del espacio" (Aguilera, 2016, p. 46). La toponimia conmemorativa involucra una práctica social, una memoria que elabora y recrea una identidad colectiva (Raposo, 2017). Identidad que sin duda es política y está en continua amenaza, disputa, reelaboración y reivindicación, ésta en particular desde el movimiento feminista.

La toponimia nos habla del sitio, del "peso de lo real, de una realidad íntimamente asociada a la de los sucesos conmemorados, que es aquí más poderosa que cualquier símbolo" (Choay, 1992, citado en Aguilera, 2016, p. 40). De ahí que sea la casa de Irán \#3037 la que se busca preservar, sin monumentos, disidente de la acción o en este caso inacción del Estado y, por supuesto, "sin permiso".

\subsection{Representaciones en Irán \#3037}

La Discoteque - Los elementos sonoros podrían interpretarse como avisos sobre las dinámicas espaciales, sobre las transiciones entre uno y otro espacio, sobre procesos de apropiación territorial y también como mecanismo de diferenciación identitaria (Berg, Duncan y Cosgrove, 2005; Cosgrove, 2002). Sin embargo, en la toponimia del Sitio de Memoria, La Discoteque hace alusión a una representación espacial que da cuenta de una estrategia para disimular los gritos provenientes de las y los torturados, y también como una forma de temporalizar esta práctica, pese a que, como han señalado las sobrevivientes, fuera del horario de oficina en el cual funcionaba La Discoteque, también eran sometidas a abuso y violación por parte de los guardias del recinto de detención. 
Los prisioneros y prisioneras del lugar recuerdan la música ambiental a todo volumen que se escuchaba constantemente para disimular los gritos de los que estaban siendo torturados en el subterráneo. Entre los artistas que sonaban estaba Julio Iglesias o la norteamericana Nydia Caro.

Había una música 'anglo', de repente también mucha música latina, Julio Iglesias y una canción de la Nydia Caro que a ellos [agentes de la DINA] les encantaba que decía 'hoy solamente canto por cantar' y que utilizaban contra nosotras: 'Vaya a cantar', nos decían. - ¿Qué significaba ir a cantar? - Delatar, entregar a alguien..., relató hace unos años en una entrevista Beatriz Bataszew (Freixas, 2019)

En otro de los relatos se hace alusión al sonido de la gravilla en el estacionamiento de la casa, como una forma de identificar cuando llegaban nuevas/os prisioneras/os al centro. El sonido anunciaba la entrada de las camionetas con detenidos y detenidas al patio de estacionamiento, quienes después de bajar y hacer ingreso a la casa, eran identificados en el vestíbulo y luego asignados a una de las dos habitaciones del primer piso, siempre vendados y sin saber quiénes les acompañaban en cada una de las habitaciones. Otro elemento auditivo al que hacen alusión las y los sobrevivientes, es el nombre que dio Ingrid Olderock a un perro entrenado para violarles: Volodia, en referencia a quien fuera posteriormente Secretario General del Partido Comunista en Chile (19901994).

La Discoteque hace alusión no solo a la música utilizada para disimular la tortura, sino que funciona como un elemento para periodizar su práctica (horarios, duración y frecuencia) y facilitar su empleo en un lugar residencial, a modo de cubrir la extrema violencia de los actos que ahí se practicaron.

La Venda - La supremacía de la visión para la descripción de los espacios y para anclar identidades ha sido ampliamente puesta en valor por la línea cultural en geografía. En cuanto significa la posibilidad de fijar un orden y jerarquía espacial, a la vez que se garantiza su reproducción (Cosgrove, 2002; Dwyer \& Alderman, 2008; Hussein, Stephens y Tiwari, 2020). También se ha estudiado como una forma de control social, problematizando sobre las ventajas de quienes manejan las formas de ver el mundo (Mahtani, 2014; McKittrick, 2002).

Después de trasponer el portón de entrada y ya en el patio de la casa los detenidos y detenidas eran sacados del vehículo con los ojos ocultos bajo grandes lentes de sol, lo que ayudaba a esconder la venda que cubría sus ojos desde el mismo momento de su detención. Los moradores de la casa vecina, desde el segundo piso de la cual era posible observar el patio de la Venda Sexy, manifiestan que ellos no se dieron cuenta de lo que realmente ocurría porque la mayor parte de las veces eran mujeres con lentes de sol las que salían de 
las camionetas, y poco después de entrar ellas en la casa, generalmente se escuchaba música de rock a alto volumen, lo que les hacía pensar que se efectuaban fiestas en esa casa en distintas horas del día.." (Matta Lemoine, 2019).El uso de la venda en la detención y secuestro y en los centros de tortura y exterminio se constituye en un elemento de control y desorientación espacial. A la vez trae al relato de las y los detenidos su función como anuladora de la personalidad, en tanto que, por motivo de la venda, les era imposible reconocerse entre ellas, identificarse y sentirse acompañadas (recordamos además que muchas de ellas y ellos no querían preguntar por los nombres de quienes les acompañaban por temor a poner en peligro a personas conocidas). De ahí que uno de los hitos de sororidad más destacados en los relatos de las sobrevivientes es cuando comienzan a entrar juntas al baño y pueden quitarse la venda.

En una ocasión una compañera me dice, vamos al baño juntas, pudimos entrar y entramos a ese baño con una ventana con una claraboya de esas de barcos y una vez en el baño, cerramos el pestillo y ambas nos sacamos la venda y ella me dice su nombre, y yo le digo el mío y nos abrazamos. Y la idea era que quién saliera primero, le avisará a la familia de la otra. Para eso era decir el nombre. Pero ahí ocurrió cómo un milagro, ambas nos habíamos conocido cuando niñas chicas. Ella era Guida Vera Almarza, la mataron después, la hicieron desaparecer. Nos contamos brevemente nuestras actividades y bueno, tuve la ocasión de verla y tener ese encuentro maravilloso con ella. (Entrevista a Nora Guillén, en Arellano; 2020, p.244.)

La Venda se utilizó habitualmente en los secuestros y en los trayectos entre el lugar de secuestro y el centro de detención y tortura, para desorientar a las víctimas dentro de los autos e impedir que éstos pudieran reconocer a quienes eran sus captores. La misma intención de desorientación espacial tuvieron los recorridos ficticios, que buscaron simular grandes distancias entre los lugares de secuestro y de reclusión. En varios de los centros de detención, tras la llegada al sitio la venda era retirada de los ojos de las y los detenidos por los agentes a cargo y se les volvía a poner cuando iban a ser sometidos a torturas, a fin de que no pudieran reconocer a sus agresores. No obstante, en la Venda Sexy, la venda se utilizaba de manera continua ${ }^{9}$ con la intención de impedir el reconocimiento entre las víctimas y los torturadores y, sin duda, de reconocer que estaba en un sector residencial y lo que esto significaba si lograban pedir auxilio.

\footnotetext{
${ }^{9}$ En los relatos de La Venda Sexy se encuentra la historia de los niños Inoska (12 años) y Wladimir (8 años), quienes fueron obligados a presenciar las torturas de su abuelo, a fin de que entregaran información sobre sus padres. En este caso, la visión es el elemento de tortura: el ver es la medida que busca quebrar a quienes están presenciando los hechos, así como a quien es víctima directa de la tortura para que delate a otros.
} 
La Venda como toponimia da cuenta del elemento de control, desorientación y des personificación de quienes fueron prisioneras y prisioneros en este centro de tortura. Releva el papel de la visión como una forma de conocer, describir y situar el espacio que nos rodea. Por consiguiente, la utilización de la venda es una forma de anular esas facultades y el poder que de ellas se desprende en quienes tienen la venda.

Sexy - El rol del cuerpo y su representación tiene una larga data de estudios. A inicios del siglo recién pasado la corriente fenomenológica francesa instala el habitar físico en el espacio, refiriendo a la carnalidad y profundiza la discusión en torno a la corporalidad como forma válida de conocimiento situado. Los estudios postcoloniales y feministas argumentan que los discursos emergen de un cuerpo y son cuerpo, representan una forma de hablar, una forma de acción social, giros que relevan el valor de las maneras de mirar y las representaciones de los cuerpos en la construcción histórica colonial del poder (Massey, 1999; Mcdermott \& Simmons, 2013; McDowell, 1996).

Por ello, y tal como lo señala Zúñiga (2018) es necesario considerar los vínculos entre cuerpo, poder y subjetividad, para comprender los impactos de los discursos y las acciones sobre estos. Para ella, el afianzamiento de una concepción degradada de lo femenino (basada en la diferencia genital), ha sido fundamental en la construcción legal del cuerpo y en cómo se ha determinado el contenido y el alcance de la subjetividad jurídica sobre dichos cuerpos.

A lo largo de la historia, sin embargo, las protecciones jurídicas de que han gozado las personas han estado subordinadas a las características de sus cuerpos individuales, o, más exactamente, a las representaciones sociales existentes sobre dicha corporalidad. El cuerpo ha sido (y es) un territorio político, un espacio disputado entre fuerzas de control y fuerzas de emancipación (Zúñiga, 2018, p.210)

En ese contexto, es relevante señalar que la violencia sexual contra el cuerpo es reconocida como una táctica de guerra con diferentes objetivos, desde la humillación al bando vencido, venganza hacia el contendor o como estrategia de terror hacia la población civil. El informe de Naciones Unidas (1998) señala que la violencia sexual supone prácticas de:

Violación, la esclavitud sexual, la prostitución forzada, el embarazo forzado, el aborto forzado, la esterilización forzada, el matrimonio forzado y todas las demás formas de violencia sexual de gravedad comparable perpetradas contra mujeres, hombres, niñas o niños, que tienen una vinculación directa o indirecta (temporal, geográfica o causal) con un conflicto" (Coomaraswamy, 1998/). 
Es así como los cuerpos de las mujeres han sido considerados constantemente como una geografía espacial que comunica un mensaje entre los hombres que perpetran la violencia hacia éstas. Así lo señala Rita Segato (2016) al establecer la violación como un mecanismo de representación del poder sobre los cuerpos subalternados y feminizados. La antropóloga se pregunta:

¿Por qué la violación obtiene ese significado? Porque debido a la función de la sexualidad en el mundo que conocemos, ella conjuga en un acto único la dominación física y moral del otro. Y no existe poder soberano que sea solamente físico. Sin la subordinación psicológica y moral del otro lo único que existe es poder de muerte, y el poder de muerte, por sí solo, no es soberanía. La soberanía completa es, en su fase más extrema, la de "hacer vivir o dejar morir" (Foucault, 2000, citado en Segato 2016). Sin dominio de la vida en cuanto vida, la dominación no puede completarse. Es por esto que una guerra que resulte en exterminio no constituye victoria, porque solamente el poder de colonización permite la exhibición del poder de muerte ante los destinados a permanecer vivos. El trazo por excelencia de la soberanía no es el poder de muerte sobre el subyugado, sino su derrota psicológica y moral, y su transformación en audiencia receptora de la exhibición del poder de muerte discrecional del dominador (Segato; 2016, p.38-39)

En Chile, en el periodo de dictadura cívico-militar hubo una violación sistemática de los derechos humanos por parte del Estado a través de diferentes mecanismos de detención, prisión, tortura, asesinato y desaparición hacia civiles, opositores del régimen o no. En ellos, la violencia sexual contra la mujer, a través de prácticas diferenciadas de abuso sexual, vejaciones, tortura, violación, no habían sido reconocidas en el periodo de dictadura ni tampoco durante los años que siguieron al retorno de la democracia, pese a que su uso fue masivo y cumplió cada uno de los tres objetivos que se señalaron anteriormente.

Se comenzaba por desnudarlas, amarrarlas de brazos y piernas, taparles la boca, tirarlas al suelo mientras se ponía música a altísimo volumen y se les aplicaba electricidad en senos y vagina, las manoseaban, algunos de los captores se masturbaban frente a ellas, para luego someterlas a ser violadas por un perro especialmente adiestrado. Luego serían objeto de las peores atrocidades sexuales imaginables en manos de sus captores que les causaron numerosas, violentas y diversas heridas físicas o psicológicas, muchas vigentes hasta nuestro tiempo. (El Siglo; 2020) 
Es probable entonces que dado lo inimaginable de las atrocidades cometidas contra las víctimas, los relatos de las mujeres sobrevivientes a la Venda Sexy y otros centros de detención y tortura fueron censurados en los recursos de amparo y en los primeros informes de violaciones a los derechos humanos que se elaboraron durante el periodo de dictadura. No obstante, la persistencia de las mujeres en la búsqueda de verdad y justicia permitió recuperar en parte los relatos de lo vivido,

Cuando revisé las declaraciones que hice en la Vicaría de la Solidaridad donde hablábamos de la violencia política sexual, en esos tiempos no le colocábamos este nombre, pero sí describíamos lo que nos había pasado. Y solamente aparecía como trato humillante y se borraba el conjunto de texto, o sea, aparecía un rótulo trato humillante. Y lo demás estaba absolutamente borrado, nadie quería escuchar eso, pero, además, de que nadie lo quería escuchar, para el sistema heteronormativo esto es parte de la tortura, es un daño colateral de la tortura. Es una cosita poca que les pasa a las mujeres. Cuando nosotras sabemos que no es una cosita poca, es algo muy grave, muy tremendo para nosotras... a diferencia de los hombres que también lo fueron, pero en mucho menor medida. [cursiva texto original] (Entrevista a Bataszew, en Arellano; 2020, p.248)

Además, es recurrente la descripción que se hace en los textos revisados de las categorías "jóvenes", "universitarias", "bonitas", "buenas mozas" para referirse a las prisioneras que estuvieron en La Venda Sexy; así la toponimia evidenciaría la naturalización del cuerpo femenino como objeto de violencia sexual.

Lo anteriormente descrito, permite traducir las experiencias de los y las prisioneras políticas en el centro de tortura Venda Sexy, desde la experiencia privada, invisibilizada y negada por el Estado y la "democracia" comprendida entre 1990 y 2020, periodo que estaría marcado por el hito de aplicación del primer fallo con perspectiva de género en Chile, en 2020. Esto implicó convertir dichas experiencias en un relato público "real" tras el fallo; un relato y una experiencia vivida que existió y es parte de esa realidad negada. Así, como refiere Rancière (2009) dicha toponimia re-escribe fenómenos que de otro modo serían irrepresentables en la "distribución de lo sensible". Esto debido a que dichas representaciones asociadas al significado del lugar permiten una lectura del Sitio y de las memorias entretejidas en las narraciones existentes sobre éste, que da cuenta del reconocimiento de una práctica de violencia diferenciada entre hombres y mujeres.

La violencia sexual contra las prisioneras es redificada entonces, como una manera de disputar las narrativas oficiales y de convertir los tratos humillantes en la comunicación oficial a la aplicación de tormentos sexuales con la intención de castigar e infligir daño, efectuando diversos tipos de torturas sexuales, "algunas con animales", como se indica en la Declaratoria de Monumentos Nacionales (2016). Por ello, y tal como 
señala Elizabeth Jelin (2002) las memorias como procesos subjetivos, anclados en experiencias y marcas simbólicas y materiales, permiten pensar y analizar el sentido del pasado, desde nuevas perspectivas y esta vez, como una traducción a la experiencia de lo público y lo judicial.

\section{Contextos y disputas en la construcción de una memoria feminista}

El año 2019 marcó un particular contexto en las disputas por la memoria en Chile y en específico la relación con el Sitio de Memoria La Discoteque - Venda Sexy. Primero, en el mes de agosto el inmueble fue vendido a una empresa privada del rubro inmobiliario. Transacción que fue acordada entre privados y de la cual el Consejo de Monumentos Nacionales señaló no tener información. Varias de las agrupaciones de derechos humanos levantaran la voz al respecto y en rechazo del acto. Particular fue la declaración del colectivo de mujeres sobrevivientes de la Discoteque - Venda Sexy, "Mujeres Sobrevivientes Siempre Resistentes", quienes, lideradas por Beatriz Bataszew, se pronunciaron críticamente sobre el rol del Estado en el resguardo y la conservación del Sitio de Memoria, además de solicitar la anulación de la venta del inmueble, que consideran el único Sitio que podría visibilizar la violencia política hacia las mujeres, así como las luchas y resistencias de éstas durante la dictadura y en democracia.

Figura 2: Baldosas por la memoria, Colectivo de mujeres sobrevivientes.

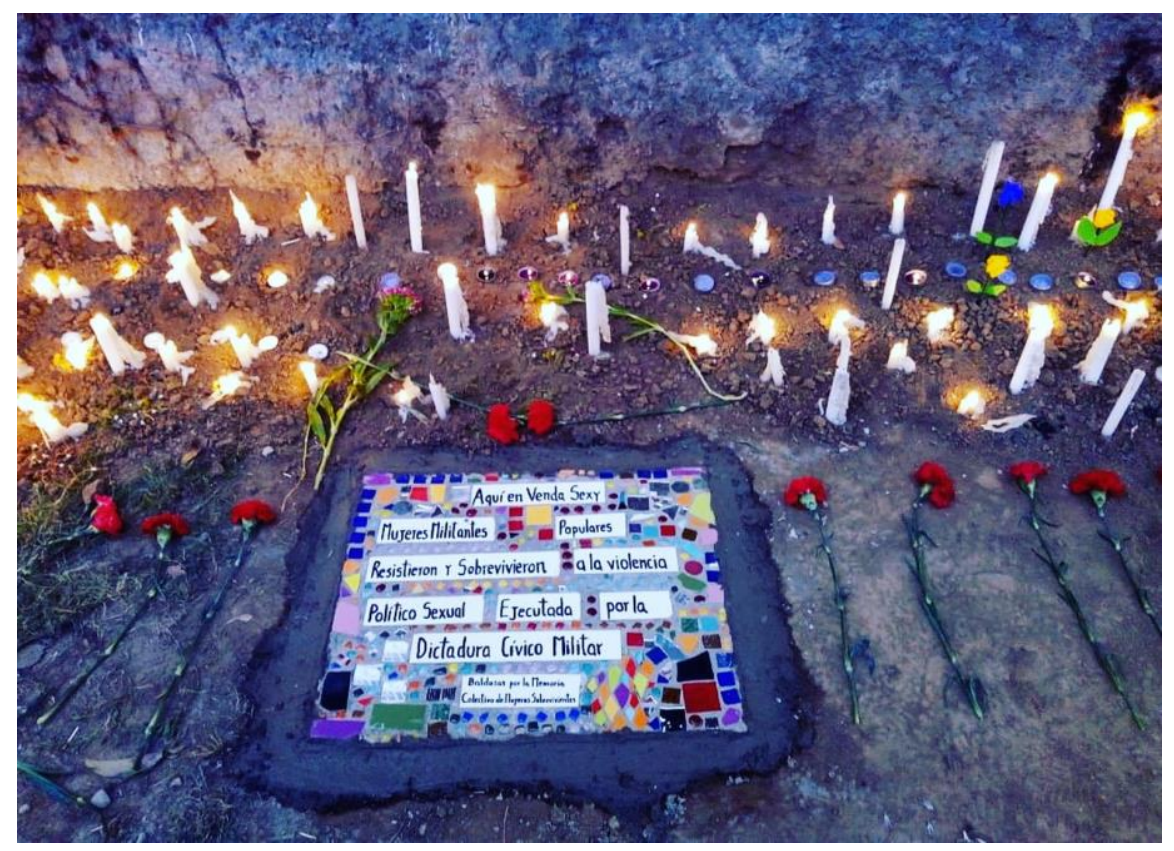

Fuente: Memorias de Rebeldías feministas - Instagram (octubre 2019). 
La segunda razón, es porque en el mes de octubre del mismo año y en pleno proceso de movilización social en Chile, las fuerzas policiales, en particular Carabineros de Chile, volvieron a incurrir en prácticas de tortura hacia las y los manifestantes en diferentes lugares de Chile ${ }^{10}$. Esto polemizó nuevamente el estado de las sanciones y justicia respecto de las violaciones a los derechos humanos en el periodo de dictadura militar y en democracia, así como la mantención de prácticas abusivas, vejatorias y directamente torturas, todas ellas institucionalizadas a nivel policial y, por ello, la necesidad de revisar de manera urgente los mecanismos que se habían acordado de "No repetición" de violencia estatal.

A ello se agrega que, tras casi un año de la venta del inmueble, el 5 de noviembre del 2020, por primera vez se condenó en Chile a cuatro generales de la DINA en un fallo ${ }^{11}$ que tuvo en cuenta la perspectiva de género. En dicho fallo se reconoció la violencia sexual aplicada de manera sistemática a las mujeres que estuvieron prisioneras en La Discoteque - Venda Sexy. De esta manera, el fallo tipificó un tipo penal diferente al secuestro agravado tal que, desde los estándares internacionales, se refiere a una forma específica de violencia contra la mujer. Este último hito es uno de los más relevantes, en tanto permite posicionar el Sitio de Memoria nuevamente como clave en la construcción de una memoria feminista y también considerar las 490 querellas y recursos de amparo ingresadas a tribunales por casos de mujeres y niñas que fueron víctimas de violaciones a los derechos fundamentales tras el 18 de octubre del 2019. De estos casos, 247 corresponden a torturas y tratos degradantes (57\%) y 112 fueron por tortura con violencia sexual (26\%) como parte de una práctica aún instalada en las policías.

Lo que más han visto son desnudamientos, algo que escapa al protocolo de Carabineros al momento de una detención. "Están obligando a

\footnotetext{
${ }^{10} \mathrm{~A}$ un año del movimiento social, el Instituto Nacional de Derechos Humanos (INDH) entregó un informe balance sobre violaciones a los Derechos Humanos en Chile, tras el 18 de octubre del 2019. En él se contabilizan 2.520 querellas y acciones judiciales, la mayoría (93\%) se concentran en contra de Carabineros, con 2.340 querellas. Le sigue el Ejército con 97 recursos, la Policía de Investigaciones (PDI) con 34, y 49 en otras entidades del Estado. "Sobre el avance de estas causas, 31 querellas están formalizadas con 78 funcionarios imputados por actos de lesa humanidad. De estos 53 están en la Región Metropolitana. Sobre las víctimas de violaciones de derechos humanos, se reportan 3.023 personas, y 163 heridos con trauma ocular. En cuanto a la tipificación de los delitos, existen 1.730 querellas por apremios ilegítimos, 460 por torturas, 101 por violencia innecesaria, 5 por homicidio, 35 por homicidio frustrados y 1 por violencias innecesaria con resulta de muerte." (Equipo Digital; 2020). ()

${ }^{11}$ El fallo a cargo del magistrado Mario Carroza indicó el delito de secuestro calificado y aplicación de tormentos con violencia sexual a seis prisioneras: Cristina Godoy, Laura Ramsay, Beatriz Bataszew, Sara de Witt, Carmen Holzapfel y Clivia Sotomayor. Además del secuestro calificado y aplicación de tormentos a Agustín Holgado, Luis Ahumada, Eugenio Alarcón y Luis Bernal. Los condenados siguen siendo los mismos ex-agentes ya condenados Raúl Iturriaga Neumann (Ejército), Manuel Rivas Díaz (PDI), Hugo Hernández Valle (PDI) y Alejandro Molina (Carabineros), por aplicación de tormentos con violencia sexual a Agustín Julio Holgado Bloch, Luis Rodolfo Ahumada Carvajal, Eugenio Ambrosio Alarcón García y Luis Humberto Bernal Venegas.
} 
las mujeres a hacer sentadillas desnudas y les revisan su cavidad vaginal para ver si es que tienen algún objeto. Eso está completamente al margen de nuestro derecho nacional y del derecho internacional" (Zamora, 2019)

Respecto del fallo de noviembre de 2020, su historia se remonta al año 2014 cuando Nieves Ayress, Alejandra Holszapfel, Soledad Castillo, Nora Brito y Beatriz Bataszew presentaron una querella por violencia política sexual, que fue acogida por tribunales. Luego, en el año 2016, Beatriz Bataszew presentó otra querella por el mismo delito contra el estado chileno, acompañada del Colectivo de Mujeres Sobrevivientes Siempre Resistentes, de las Feministas Autoconvocadas y de la Corporación Humanas,

Queríamos decir que la utilización de un poder sexualizado sobre las mujeres era una expresión política del terrorismo de Estado hacia las mujeres que luchaban, entonces ahí salió el concepto del enunciado de la violencia política sexual [cursiva de las autoras]. Nosotras lo planteamos por varias razones: la primera era porque en la sociedad patriarcal y en nuestro sistema judicial heteronormativo no se diferencia la tortura de la violencia política sexual, por ende, la violencia político sexual queda absolutamente oculta ... no hay ni siquiera una condena de un día por violación o cualquier otro abuso que se haya cometido contra las mujeres en los tiempos de la dictadura militar. Estoy hablando de violación, de utilización de animales amaestrados, estoy hablando de electricidad en nuestros genitales, estoy hablando de embarazo forzado, estoy hablando de aborto forzado, etc. La mayoría de esas mujeres no hemos recibido ningún tipo de justicia. Entonces acuñamos este concepto inicialmente como una trasgresión a la identidad corporal y sexual de las mujeres con un sentido claramente político contrainsurgente para impedir o castigar a las mujeres que luchan por sus derechos o contra las opresiones, y lo hicimos muy relacionado al artículo 7 G13 del estatuto de Roma. (Entrevista a Bataszew, en Arellano, 2020, p.246)

Según lo señalado por Eduardo Contreras en una entrevista ${ }^{12}$, tras el fallo que tipificó la violencia de género, sexual y sistemática a seis de las prisioneras en La Discoteque - Venda Sexy; éste hace eco de un proceso que comenzó el año 1998 cuando por primera vez el grupo de mujeres sobrevivientes a este centro de tortura y exterminio mandató una investigación judicial ${ }^{13}$ para los crímenes que acontecieron en este lugar.

\footnotetext{
12 Entrevista extraída de: El Siglo (18 de noviembre de 2020) La Venda Sexy. Recuperado el 3 de febrero $2021 \mathrm{https}: / /$ elsiglo.cl/2020/11/18/la-venda-sexy/

13 Tras la desaparición del expediente en el año 2016 se ingresó un nuevo expediente en el 34 Juzgado del Crimen de Santiago, a cargo del Ministro de la Corte, Mario Carroza, en el que a partir de la foja número 5824, puede leerse la Sentencia de primera instancia para el caso denominado "Venda Sexy". En él se señala que "excesos que constituyeron aberraciones deshumanizadas ejecutadas por agentes del Estado, en los que no solo se les infringieron graves sufrimientos físicos y psíquicos, sino que hubo atropellos al desamparo en que se encontraban para así ejecutar
} 
Sin embargo, en ese tiempo, el expediente "se extravió" - indica el abogado- porque "los Tribunales solo investigaban casos de detenidos desaparecidos, relegando al olvido los casos de ejecutados y de torturados."

Lo ocurrido en Venda Sexy, sostiene Beatriz, estaba completamente fuera del imaginario represivo de ella y otros militantes de movimientos de izquierda, en medio de los años más crudos de la dictadura. (...) Esto no solo fue violencia sexual, fue violencia política sexual, que tenía como objetivo domesticarnos, disciplinarnos y particularmente castigarnos, porque éramos mujeres que luchábamos decididamente contra la dictadura". (Entrevista a Beatriz Betazsew, 2020)

En esta misma entrevista se hace alusión al valor del fallo, pero también se abordan sus limitantes, por ejemplo, al no considerar el elemento político de esta violencia, para Beatriz significa que se juzga a quienes orquestaron este instrumento de terrorismo de Estado. Pero el tiempo que demoró en salir el falló da cuenta de una justicia tardía y, por tanto, fallida.

Otro hito para destacar en este proceso de visibilidad pública de las memorias del Sitio Venda Sexy fue que el 29 de octubre de 2020, apenas una semana antes de la publicación del fallo por parte del Juez Carrosa, se estrenó la obra de teatro "Irán \#3037 [violencia político sexual en dictadura]": obra sobre la "Venda Sexy", a través de una plataforma online de la Vicerrectoría de Extensión y Comunicaciones de la U. de Chile y de manera conjunta con la Plataforma Escena Crítica y Memoria, a cargo de la puesta en escena, y las cátedras de DDHH y Amanda Labarca de la U. de Chile ${ }^{14}$. Este hito marca una nueva apuesta por la "traducción" de la experiencia de tortura y violencia política sexual, desde la experiencia personal, a la experiencia pública, visibilizándola, dotándola de realidad y poniéndola en el imaginario colectivo como un crimen que existió y del cual es necesario reparación y justicia.

Todo lo anterior es fundamental para entender los discursos de las y los sobrevivientes y la misma toponimia del lugar, como parte fundamental de la construcción de una narrativa de memoria feminista, que rescata la resistencia de las mujeres ante la

las agresiones de violencia sexual sistemáticas, conductas que de por sí fueron deleznables y que prevalecieron en los interrogatorios, por lo mismo, ellas obligan a este sentenciador a construir un tipo penal separado al de secuestro agravado, por constituir conductas que en una mirada a los estándares internacionales, han de ser visibilizadas y exaltadas por su gravedad y deshumanización, toda vez que ellas instituyen una forma específica de violencia contra la mujer". (BioBio Chile; 2020, p.1) ()

${ }^{14}$ Obra dirigida por Patricia Artés, en la que se cuenta la vida de una familia común y corriente que habita una casa (la casa de Irán \#3037) Es una historia completamente contextual si se piensa que hubo una familia que vivió durante muchos años en esta casa, antes de venderla a su actual dueño, quienes además han señalado en distintas entrevistas su experiencia de índole fantasmagórica, al vivir ahí. 
dictadura, posicionando los cuerpos femeninos como receptores de una violencia particular, política, sexual y simbólica. Alejandra Holzapfel, , se refiere a estas tramas de resistencia entre las mujeres que pasaron por Venda Sexy, señalando lo siguiente:

La resistencia consistía en eso: en no rendirse en medio de la miseria". En la entrevista del año 2017 señala, "Descubrimos que no nos violaban cuando estábamos con la regla. Como había compañeras que tenían heridas de balazo o de distintas cosas, entonces nos organizamos para que nos dejaran trapitos con sangre debajo de la taza del WC, y nosotras nos poníamos esos paños con sangre cuando éramos llevadas a la tortura y a la violación. Un día nos dicen: y a estas weonas que les pasó que están todas con la regla, y ese día no violaron a nadie. Era una forma de protegernos, dentro de esa situación tan vulnerable, porque igual tuvimos capacidad de pensar cómo hacerlo, cómo defendernos ante tanta atrocidad. (Arellano, 2020, p.244)

En este aspecto y como señala Elizabeth Jelin (2002) las narrativas del pasado y su control dan cuenta de cómo se imaginan o se espera construir las narrativas del futuro, de manera tal que la mantención de prácticas de violencia de género por parte de las policías en el contexto del movimiento social de octubre del año 2019, acusa una deuda con la memoria de las mujeres torturadas y desaparecidas en dictadura (Arellano, 2020). A la vez que posiciona estas mismas memorias y su especificidad en el relato del Chile actual, movilizado y feminista (Zerán, 2018).

Un segundo elemento para mí muy importante es que yo conocí el feminismo, lo que hoy día lo llamamos feminismo .... algo demostró en el sentido de que todos estos dolores y estos sufrimientos estaban muy permeados a los estereotipos que demostramos las mujeres, la vergüenza, la culpa, etc. Entonces como que noté en mi cuerpo también, que mucho de las cosas que sentía, las tenía que sentir en las cárceles como el estereotipo femenino. Y fue para mí una tremenda liberación para mí entender eso y salirme de eso. Después yo me hice mucho más feminista digamos, pero en ese minuto para entender eso, fue realmente una posibilidad de construir mi sanación también. (Entrevista a Beatriz Bataszew, en Arellano, 2020, p.246)

De ahí se abren y multiplican las posibilidades de (re)leer y (re)significar las experiencias propias y compartidas de las mujeres sobrevivientes a los centros de detención y tortura, en trama feminista, activando la memoria, levantando la violencia política sexual en los espacios de deliberación política: en la calle, en los tribunales y en la conversación diaria. Además, exigiendo su reconocimiento y tipificación, en el contexto de la urgente necesidad de modificaciones políticas y reglamentarias para el actuar de las policías y la garantía de no repetición. 


\section{Conclusiones}

En línea con lo que plantea Claudia Arellano (2020) y siguiendo a Elizabeth Jelin (2002), las experiencias de las mujeres en las dictaduras en América Latina y en los conflictos armados en el mundo son y han sido siempre diferenciadas de las de los hombres, debido a las jerarquías de género y la objetivación del cuerpo femenino como objeto de violencia sexual. Por esto, es fundamental reconocer y tipificar de manera diferenciadas estos actos de terrorismo de Estado contra las mujeres y proteger los elementos materiales que testifican y permiten reconfigurar la memoria de las experiencias de mujeres que sufrieron crímenes de violencia política y sexual, como una memoria feminista, activa y critica ante las situaciones del presente.

La documentación de las violaciones a los derechos humanos, su traslación a la esfera pública y el valor - hoy - conmensurable de esos relatos, nos permiten entender, casi 50 años más tarde, el potencial de esos recursos para construir una memoria feminista y profundizar en el significado y la constitución de los objetos que hicieron parte de un espacio-tiempo de violencia, tortura y desaparición como femigenocidios (en palabras de Rita Segato; 2016).

Por ello, son relevantes los actos ciudadanos que perpetúan estas memorias. En ese contexto, destacamos la masiva conmemoración de un nuevo aniversario del Golpe de Estado cívico militar chileno, por parte de las sobrevivientes del Centro de torturas La Discoteque - Venda Sexy en las afueras de la Casa de Irán \#3037, el domingo 12 de septiembre del año 2021. Este acto da cuenta una vez más de las resistencias que hacen las mujeres sobre las memorias feministas, de su articulación y también de su autogestión. Lo anterior, mediante la colocación de un cartel en madera, alusivo a la casa de torturas en el mismo sitio en que ellas, años atrás, instalaron una placa conmemorativa bajo uno de los muros perimetrales de la casa. Con este acto se pretende insistir en la relevancia de la declaración y posesión del sitio de memorias por parte de las colectivas y organizaciones que han mantenido y reclamado la recuperación de estas memorias, a pesar de la desidia del Estado ${ }^{15}$.

Lo anterior deja en evidencia, tal como han señalado las sobrevivientes, en la voz de Beatriz Bataszew, que:

Estamos aquí sin pedirle permiso a nadie en un espacio que ya es nuestro, y estamos convencidas que juntarnos aquí una y otra vez en esta casa que quiso aniquilar los sueños y las luchas de las compañeras que aquí desaparecieron y también de las que sobrevivieron, sobrevivimos a tal ignominia, merece ser señalada, merece ser nombrada. No exigimos ni al

\footnotetext{
${ }^{15}$ Lamentablemente el nuevo cartel fue sustraído en menos de 24 horas por desconocidos.
} 
Estado ni a ninguna de sus organizaciones que lo haga, lo hacemos entre y con nosotras, nosotres; no es una victimización, ni mucho menos para escarbar las heridas; lejos estamos de ser víctimas. Lo hacemos porque construimos nuestros recuerdos insumisos en contra de la neoliberalización de la memoria, de las políticas del olvido, de los pactos de silencio y también de las transacas que hacen a espaldas con nuestros dolores, cuerpas y vidas. Nuestro pesar, que es nuestro, lo resignificamos y lo dotamos de dignidad y rebeldía... (discurso conmemoración aniversario 48 del Golpe Civico-Militar y de instalación del Cartel "Casa de tortura "Venda Sexy"', organizado en Sitio de Memoria Venda Sexy, septiembre, 2021)

Estamos convencidas que la casa de Irán \#3037 Sitio de Memoria "La Discoteque - Venda Sexy" debe ser reconocida por el Estado como un sitio oficial en el cual se violaron los derechos humanos más básicos de las personas que ahí fueron llevadas por agentes de la dictadura. Y por ello, consideramos que urge la compra del inmueble por parte del Estado chileno, para su funcionamiento como Centro de Memorias y su resguardo material, así como para alojar diferentes acciones y actividades en línea con el carácter diferenciado de este centro de detención y tortura. Un espacio físico en el que se materializa la memoria feminista. No obstante, y de la mano de las palabras de Beatriz Bataszew, coincidimos en que la posesión efectiva de los sitios de memoria se realiza mediante actos de resistencia de sus sobrevivientes y de la ciudadanía que lucha activamente por mantener dichas memorias. En el caso del centro de torturas "La Discoteque - Venda Sexy" estas resistencias han sido posibles gracias al rol activo de las mujeres sobrevivientes y otras resistencias colectivas feministas y disidentes, quienes han acompañado estas luchas durante los cinco años que han transcurrido desde la declaratoria del Sitio de Memoria por parte de Monumentos Nacionales y, por supuesto, mucho tiempo antes, desde que se denunció este espacio y su rol diferenciado al de otros centros de detención y tortura durante la represión política militar.

Por esta razón dejamos abierta la discusión sobre cómo las organizaciones de memoria, y no el Estado, son quienes han hecho posesión simbólica y material de estos espacios y, como en el caso de este inmueble (aún de propiedad privada), tales actos de resistencia y posesión se realizan "sin permiso"16.

${ }^{16}$ El 21 de septiembre de 2021, posterior a este escrito, se lanzó el libro "La Violencia Política Sexual es terrorismo estatal: Aproximaciones desde la experiencia y la memoria contra la impunidad en Chile" del Colectivo Mujeres Sobrevivientes Siempre Resistentes y Memorias de Rebeldías Feministas. El libro está disponible de acceso abierto. Para más información visitar en Instagram@memoriasrebeldiasfeministas. 
Revista Punto Género N. 16 Diciembre de 2021

ISSN 2735-7473 / 24- 50

Figura 3: Acto Conmemoración 12 de septiembre 2021.

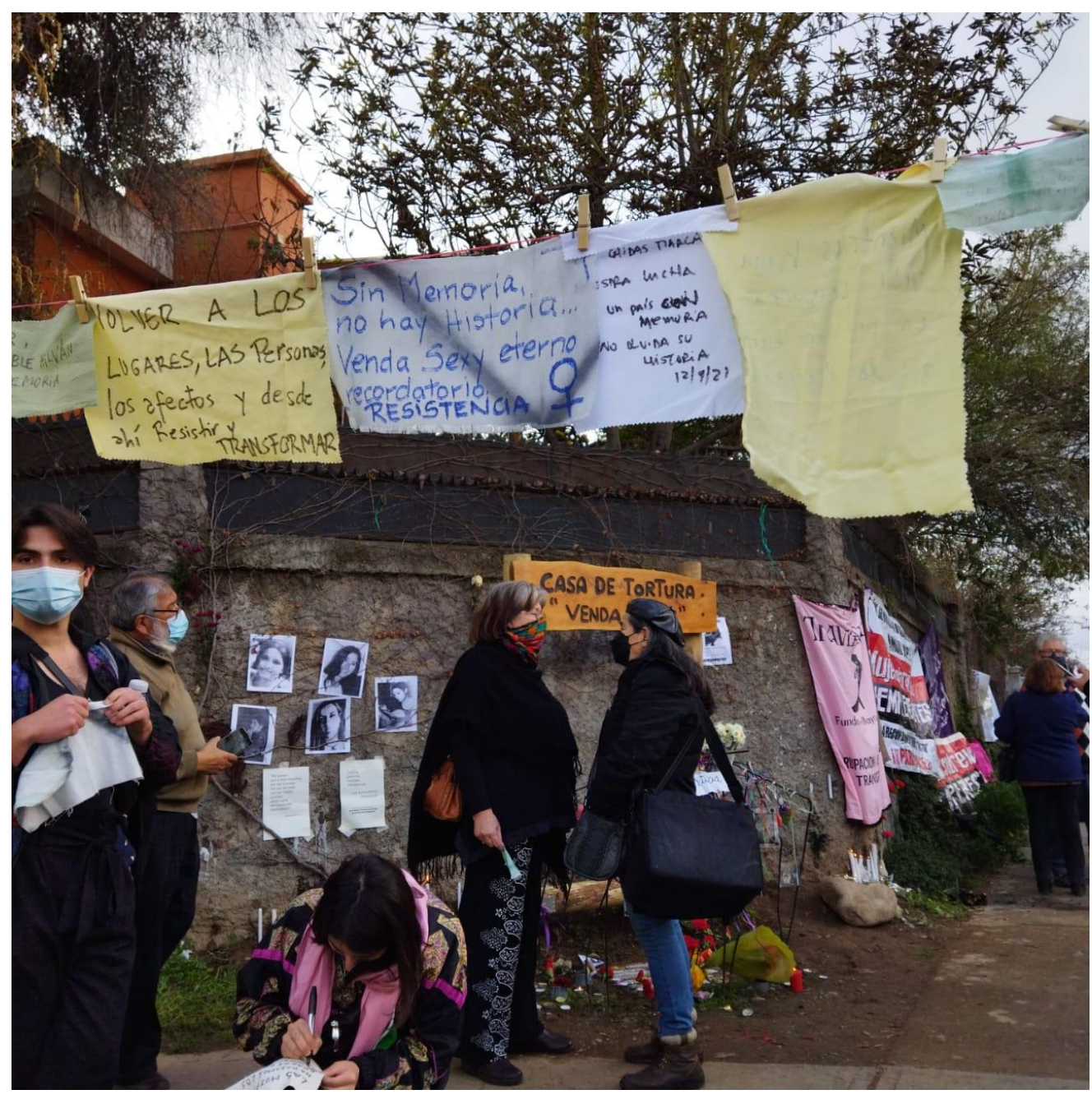

Fuente: Archivo propio (2021). 
Revista Punto Género N․o 16 Diciembre de 2021

ISSN 2735-7473 / 24- 50

Figura 4: Cartel elaborado e instalado por Colectivas Memorias de Rebeldías Feministas y Mujeres Sobrevivientes Siempre Resistentes.

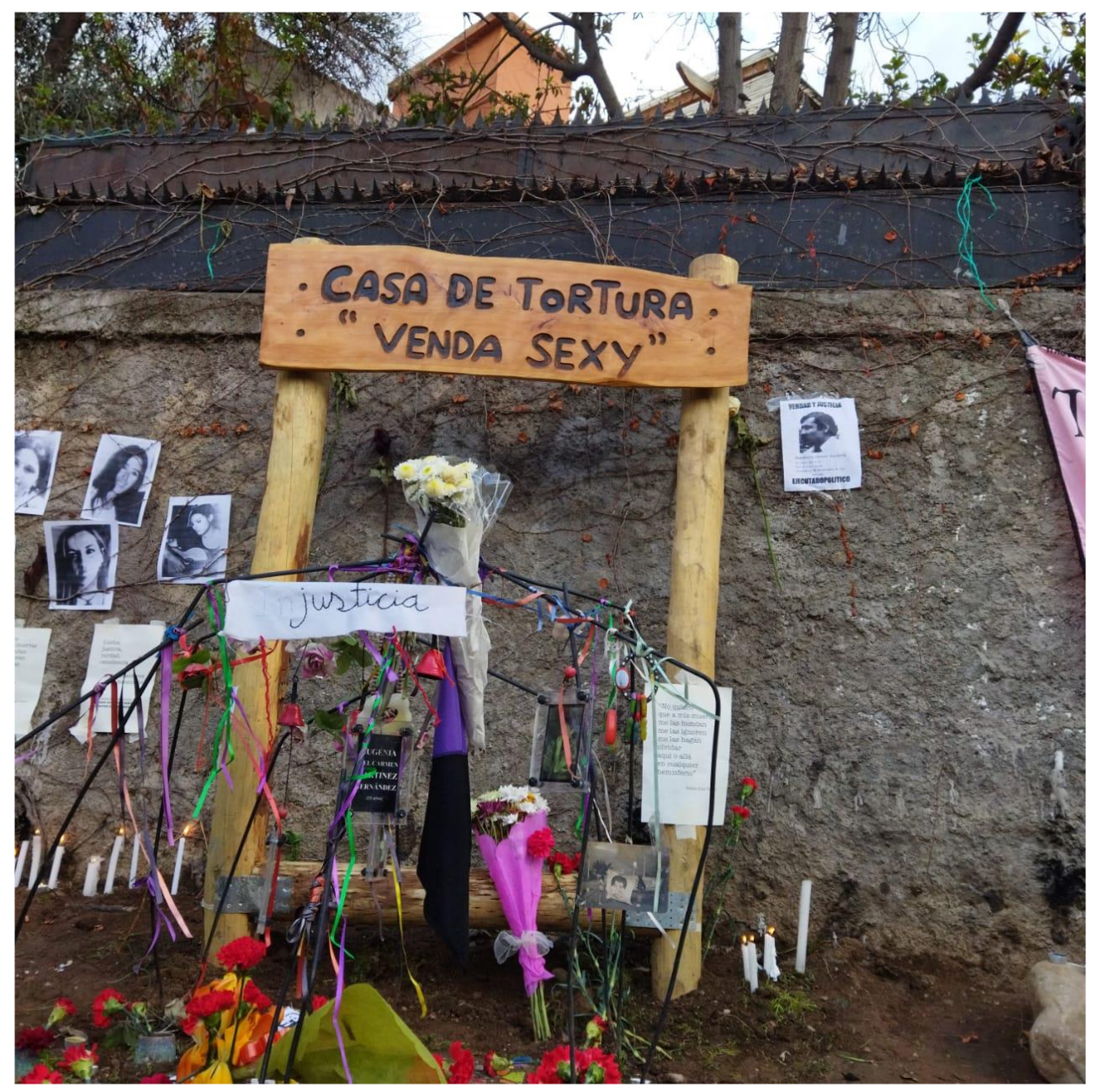

Fuente: Archivo propio (2021).

\section{Bibliografía}

Aguilera, C. (2016). El retorno del monumento. Forma urbana y espacio vivido de la memoria pública de la violencia política en ciudades posconflicto; el caso de Santiago de Chile. Pontificia Universidad Católica de Chile. 
Revista Punto Género N ․ 16 Diciembre de 2021

ISSN 2735-7473 / 24- 50

Arellano, C. (2020). Venda Sexy: Memorias no oficiales de un centro de detención. Revista Latinoamericana de Derechos Humanos, 30(2), pp.237-254. https://doi.org/10.15359/rldh.30-2.11

Arendt, H. (1999). Eichmann en Jerusalén. In 4º (pp. 60-69). Lumen, S.A.

Berg, L. D., Duncan, J. S., \& Cosgrove, D. (2005). Cosgrove, D. 1985: Social formation and symbolic landscape. Totawa, NJ: Barnes and Noble. Progress in Human Geography, 29(4), pp.475-482. https://doi.org/10.1191/0309132505ph565xx

Biobio Chile (2020, mayo 11) Condenan a 15 años de cárcel a ex agentes de la DINA por secuestros $y$ torturas en Venda-Sexy [Periódico electrónico]. https://www.biobiochile.cl/noticias/nacional/regionmetropolitana/2020/11/05/condenan-a-15-anos-de-carcel-exagentes-de-ladina-por-secuestros-y-torturas-en-venda-sexy.shtml)

Cerrón-Palomino, R. (2015). Toponimia andina: Problemas y métodos. Lexis (Peru), 39(1), pp.183-197.

Coomaraswamy, R. (1998) Informe ONU E/CB.4/1998/54 Informe de la misión a Rwanda para estudiar la violencia contra la mujer en situaciones de conflicto armado. Comisión de Derechos Humanos del Consejo Económico y Social de Naciones Unidas. https://undocs.org/pdf?symbol=es/E/CN.4/1998/54

Comisión Nacional sobre Prisión Política y Tortura (2005) Informe Comisión Nacional Prisión Política y Tortura, Informe Valech. La Nación. https://bibliotecadigital.indh.cl/handle/123456789/455

Consejo de Monumentos Nacionales (2016) Decreto N²77 Declara Monumento Nacional en la Categoría de Monumento Histórico al Sitio de Memoria Centro de Detención denominado "Venda Sexy-Discoteque". https://www.bcn.cl/leychile/navegar?i=1096022

Cosgrove, D. (2002). Observando la naturaleza: el paisaje y el sentido europeo de la vista. Boletin de La Asociacion de Geografos Españoles, 34, pp.63-89. https://doi.org/10.21138/bage.428 
Revista Punto Género N. 16 Diciembre de 2021

ISSN 2735-7473 / 24- 50

Dwyer, O. J., \& Alderman, D. H. (2008). Memorial landscapes: Analytic questions and metaphors. GeoJournal, 73(3), pp.165-178. https://doi.org/10.1007/s10708008-9201-5

El Siglo. (2020, noviembre 18). La "Venda Sexy" - El Siglo [Periódico electrónico]. El Siglo. Semanario Digital. https://elsiglo.cl/2020/11/18/la-venda-sexy/

Equipo Digital. (2020, octubre 17). INDH: existen 2.520 querellas por violaciones a los Derechos Humanos a un año del 18 de octubre [Medio electrónico]. Televisión Universidad de Concepción. https://www.tvu.cl/prensa/2020/10/17/indhexisten-2-520-querellas-por-violaciones-a-los-derechos-humanos-a-un-anodel-18-de-octubre.html

Freixas, M. (2019, septiembre 11). Dictadura chilena: La Venda Sexy, el centro de tortura de Pinochet contra la mujer que se vende al mercado inmobiliario [Periódico electrónico]. Público. https://www.publico.es/internacional/dictadura-chilenavenda-sexy-centro-tortura-pinochet-mujer-vende-mercado-

inmobiliario.htmlHussein, F., Stephens, J., \& Tiwari, R. (2020). Towards Psychosocial Well-Being in Historic Urban Landscapes: The Contribution of Cultural Memory. Urban Science, 4(59), pp.1-15.

Jelin, E. (2002) Los trabajos de la memoria. Siglo XXI.

Mahtani, M. (2014). Toxic geographies: Absences in critical race thought and practice in social and cultural geography. Social and Cultural Geography, 15(4), pp.359367. https://doi.org/10.1080/14649365.2014.888297

Massey, D. (1999). Philosophy and politics of spatiality: Some considerations The hettnerlecture in human geography. Geographische Zeitschrift, 87(1), pp.1-12.

Matta Lemoine, P. A. (2019, agosto 26). La Venda Sexy y la Invisibilización de la Mujer [Blog institucional]. Colegio de Arqueólogos y Arqueólogas de Chile. https://colegiodearqueologos.cl/la-venda-sexy-y-la-invisibilizacion-de-lamujer/Mcdermott, M., \& Simmons, M. (2013). Embodiment and the Spatialization of Race. Contemporary Issues in the Sociology of Race and Ethnicity, 445(1), pp.153-168. https://about.jstor.org/terms 
Revista Punto Género N. 16 Diciembre de 2021

ISSN 2735-7473 / 24- 50

McDowell, L. (1996). Spatializing Feminism Geographic perspectives. In N. Duncan (Ed.), Body Space (Routledge, pp. 28-44).

McKittrick, K. (2002). Their Blood Is There, and They Can't Throw It Out: Honouring Black Canadian Geographies. TOPIA: Canadian Journal of Cultural Studies, 7, pp.27-37. https://doi.org/10.3138/topia.7.27

Memoria Viva. (2019, diciembre, 6) Recinto Dina “La Venda Sexy” [página web]. Memoria Viva.

(https://www.memoriaviva.com/Centros/00Metropolitana/Recinto_DINA_venda _sexy.htm.) Rancière, J. (2009). El reparto de lo sensato. Estética y política.

Raposo, G. (2017). La memoria emplazada: proceso de memorialización y lugaridad en la post-dictadura. Espacios,

https://doi.org/10.25074/07197209.6.354

Salgado, D. (2020, 05 noviembre). Condenan a 15 años de cárcel a exagentes de la DINA por secuestros y torturas en "Venda Sexy". https://www.biobiochile.cl/noticias/nacional/regionmetropolitana/2020/11/05/condenan-a-15-anos-de-carcel-exagentes-de-ladina-por-secuestros-y-torturas-en-venda-sexy.shtmISegato, R. (2016). La guerra contra las mujeres. Traficantes de sueños.

Segato, R. (2014). Las nuevas formas de la guerra y el cuerpo de las mujeres. Pez en el agua.

Servicio Nacional del Patrimonio Cultural (2016). CENTRO DE DETENCIÓN LA VENDA SEXY A UN PASO DE SER DECLARADO MONUMENTO NACIONAL. https://www.patrimoniocultural.gob.cl/portal/Contenido/Noticias/59298:Centrode-detencion-la-Venda-Sexy-a-un-paso-de-ser-declarado-MonumentoNacional

Oficina del Alto Comisionado de Derechos Humanos de Naciones Unidas (2019). Informe sobre la Misión a Chile, 30 de octubre - 22 de noviembre. https://www.ohchr.org/Documents/Countries/CL/Report_Chile_2019_SP.pdf 
Revista Punto Género N․ 16 Diciembre de 2021

ISSN 2735-7473 / 24- 50

Zamora, R. (2019, octubre, 26) Denuncian violencia sexual y torturas a mujeres y LGBT+ por Carabineros [página web]. Agencia Presentes. https://agenciapresentes.org/2019/10/26/chile-denuncian-violencia-sexual-ytorturas-a-mujeres-y-personas-lgbt-por-carabineros-y-ejercito $/$.

Zerán, F. (2018) Mayo feminista. La rebelión contra el patriarcado. LOM EdicionesZúñiga, Y. (2018). Cuerpo, Género y Derecho. Apuntes para una teoría crítica de las relaciones entre cuerpo, poder y subjetividad, Lus et Praxis, (24), 3, p.209254. 